\title{
ESCOLAS PRIMÁRIAS DE PORTO VELHO/RONDÔNIA E A MILITARIZAÇÃO DA INFÂNCIA (1930/1940)
}

\author{
Marijâne Silveira da Silva*
}

\begin{abstract}
RESUMO: Este texto trata sobre as representações e práticas de militarização da infância idealizadas nos atos oficiais e localizadas no cotidiano das escolas primárias de Porto Velho/Rondônia, nas décadas de 1930/1940. É um estudo de natureza historiográfica e tem como referencial teórico autores da História Cultural, fundamentado nas obras de Roger Chartier $(1989,1990)$ e Certeau (1982). As fontes utilizadas são Regulamentos, Programas e Planos de Ensino, periódicos da época e imagens iconográficas, encontradas no Museu da Memória Rondoniense (Porto Velho-RO), no acervo digitalizado pela "História da Educação e da Infância" (FCC), no Arquivo Público de Mato Grosso (APMT) e na Biblioteca Nacional Digital (BN Memória). O estudo analisou as disciplinas que destacaram em seus programas as ideias de civismo, patriotismo, nacionalismo que influenciaram na formação moral e cívica dos alunos da escola primária, como: História, Geografia, Educação Moral e Cívica, Educação Phisica, Educação Hygienica e Canto. Nestas disciplinas, percebe-se também as práticas de militarização instituídas nas sessões cívicas referentes a todos os feriados nacionais e estaduais, com o objetivo de prepará-los para a participação nas festas cívicas. Os escolares participavam de todos os momentos festivos em comemoração as datas cívicas, com desfiles de batalhões em marcha, bandeiras e com vasto programa festivo que eram disseminados na imprensa periódica local. Conclui-se que muitas práticas, presentes nas escolas primárias da Primeira República, continuaram sendo disseminadas na Era Vargas, com a finalidade de desenvolver nas crianças o sentimento de patriotismo, as virtudes cívicas, a moralização dos hábitos, a eugenia e a disciplina corporal.
\end{abstract}

ABSTRACT: This text details the the representations and practices of military education present in the primary schools of Porto Velho/Rondônia, in the 1930s / 1940s, as materialized in patriotic, civic-military activities, in the regulations and in the official teaching programs. It is a study of a historiographical nature and has as a theoretical reference authors of Cultural History, based on the works of Roger Chartier $(1989,1990)$ and Certeau (1982).The sources used were found in the archives of the Museu da Memory Rondoniense (Porto Velho-RO), in the collection digitized by the "History of Education and Childhood" (FCC), at the National Digital Library (BN Memory), as official documents, iconographic images and periodicals of the time. The study analyzed the disciplines that highlighted in their programs the ideas of civism, patriotism, nationalism that influenced the moral and civic education of primary school students, such as: History, Geography, Moral and Civic Education, Physical Education, Hygienic Education and Singing. In these disciplines, the militarization practices instituted in civic sessions referring to all national and state holidays are also noticed, with the purpose of participation in civic celebrations. School children participated in all the festive moments celebrating such civic dates with parades of battles, flags and with a vast festive program disseminated in the local periodic press. It is concluded that these practices, present in many primary schools of the first Republic, continued to be widespread in the Vargas Era, with the objective of developing in children the feeling of patriotism, civic virtues, the moralization of habits, habits, eugenics and corporal discipline.

PALAVRAS-CHAVE: Escolarização da infância; Instrução militar; Escola Primária.

KEYWORDS: Childhood schooling; Military Education, Primary School.

\section{INTRODUÇÃO}

INTERLETRAS, ISSN N 1807-1597. V. 9, Edição número 34. Outubro, 2021/ Março de 2022- p. 
Este texto apresenta resultados de uma pesquisa desenvolvida em âmbito de pósdoutoramento. ${ }^{1}$ Tem como objetivo investigar as representações e práticas de militarização da infância idealizadas nos atos oficiais e localizadas no cotidiano das escolas primárias De Porto Velho (atual capital de Rondônia), nas décadas de 1930/1940. Para tanto, as fontes utilizadas na análise são Regulamento, Programas e Planos, periódicos da época e imagens iconográficas, encontradas no arquivo do Museu da Memória Rondoniense (Porto Velho-RO), no acervo digitalizado na página "História da Educação e da Infância" (FCC) e na Biblioteca Nacional Digital (BN Memória).

Trata-se de um estudo de natureza historiográfica e tem como referencial teórico autores que fazem parte do campo da História Cultural, fundamentado nas obras de e Michel de Certeau (1982) e Roger Chartier $(1989,1990)$ nos conceitos de práticas e representações, por possibilitarem novas perspectivas para o estudo historiográfico da escolarização da infância. E, especificamente para este artigo, autores que tratam da História do Currículo e das disciplinas escolares, como Goodson $(1995,1997)$ e Chervel (1990).

No período delimitado, a cidade de Porto Velho encontrava-se geograficamene, localizada na região denominada de Guaporé, entre os vales dos Rios Madeira e Guaporé. Essa região pertencia, em grande parte, ao Estado de Mato Grosso e parte ao Estado do Amazonas. Com o desmembramento das terras a região foi transformada em Território Federal Guaporé (1943-1956) e, em seguida, passou a ser denominada Território Federal de Rondônia (1956-1980). Neste sentido, o período delimitado e o lócus da pesquisa perpassam pela Era Vargas e, com isso, pelos processos migratórios e de colonização que sedimentaram mudanças sociais advindas com a transformação da região, tanto no aspecto geográfico, político e populacional que impactaram diretamente na área educacional.

Durante as décadas de 1910 a meados de 1940, a escolarização da infância dessa região foi administrada pelos governantes que atuaram em Mato Grosso e no Amazonas (Porto Velho estava sob a jurisprudência deste estado). Neste cenário, apareceram projetos voltados para a escolarização das crianças e várias modalidades escolares passaram a coexistir na região como: escolas isoladas mistas, rurais, urbanas, grupos escolares e jardins de infância, de ensino público ou particular. Neste período, as escolas estavam normatizadas por Regulamentos da Instrução Pública dos respectivos estados, sendo assim, serão utilizados neste texto como fontes de análise.

A partir de 1943 essa região passa a ter uma nova conjuntura política, geográfica, econômica, social e educacional. Dando continuidade à política de ocupação dessa região, o primeiro governador do Território, Major Aluízio Ferreira fixou algumas metas que considerou como essenciais para serem implantadas nos três primeiros anos de sua gestão, com setores considerados como fundamentais para a administração territorial, sendo relativos à agricultura, a saúde pública, a educação e aos transportes. Estes setores foram

\footnotetext{
${ }^{1}$ Pesquisa realizada com financiamento PNPD/Capes (2019-2020) no Programa de Pós-Graduação em Educação da UFMT (PPGE/IE).
}

INTERLETRAS, ISSN N 1807-1597. V. 9, Edição número 34. Outubro, 2021/ Março de 2022- p. 
sendo organizados para receber o fluxo de migração previsto para a mais recém-criada unidade federada. (SOUZA, V., 2002).

Após três meses à frente do cargo, o major Aluízio Ferreira editou o decreto n. ${ }^{\circ} 2$, estabelecendo a Organização Administrativa, por meio do qual foram criados a Secretaria Geral (Assessoria Administrativa do Governador) e os órgãos executores. No entanto, a organização administrativa do Território Federal do Guaporé só fora regulamentada pelo decreto-lei $n^{0} 7.772$, de 23 de julho de 1945. Dentre os órgãos que compunham essa administração, foi criada a Divisão de Educação (D.E.), cujas finalidades consistiam em:

I - promover, orientar e fiscalizar o ensino em todo o Território;

II - manter estabelecimentos escolares de grau e natureza compatíveis com as possibilidades da região;

III - organizar, manter e auxiliar, quando de iniciativa privada, instituições complementares do ensino ou que visem o desenvolvimento cultural da população. (BRASIL, Decreto-lei no 7.772, de 23 de julho de 1945, Art. $7^{\circ}$ )

A partir deste período, a Divisão de Educação do Território passou a normatizar todas as ações oficiais relativas ao ensino primário. Sendo assim, foi feita a seleção de documentos oficiais do Estado do Amazonas que se mostraram importantes para compreender algumas práticas de militarização da infância que se fizeram presentes nas escolas primárias de Porto Velho (atual capital de Rondônia), nas décadas de 1930/1940. Essas práticas foram materializadas nas atividades de cunho patriótico, cívico-militar, nas regulamentações e nos programas oficiais de ensino.

O termo militarização da infância está respaldado nas investigações de Rosa Fátima de Souza (2002; 1998), que ao estudar a origem da educação militar nas escolas primárias paulistas, constatou a introdução de várias disciplinas nos programas de ensino, como Ginástica e Exercícios Militares, sendo que a prática desta gerou a formação dos batalhões infantis. A autora constatou ainda, que com a decadência dos exercícios militares, por volta de 1914, muitas escolas primárias acabaram abolindo sua prática, mantendo somente a Ginástica. Logo em seguida, surge a ideia de substituir os batalhões escolares pelos agrupamentos de escoteiros. Mas, Souza (2002, p. 109) ressalta: "Os exercícios militares e os batalhões infantis estavam fadados ao esquecimento, mas não o espírito militar inspirador da educação física, moral e cívica que viria a se firmar durante muitas décadas na escola paulista mediante a prática do escotismo".

Mediante o exposto, a questão que se pretende responder neste artigo é: Quais as representações e práticas de militarização da infância se fizeram presentes nas escolas primárias do Guaporé (Rondônia), nas décadas de 1930/1940? Para tanto, procurei investigar nos Planos-Programas e indicações para o ensino primário as seguintes disciplinas: História, Geografia, Educação Moral e Cívica, Educação Phisica, Educação Hygienica e Canto. Em seguida, analisar algumas práticas de militarização da infância representativas da materialização destas ideias no cotidiano das escolas primárias da época, disseminadas na imprensa local e em imagens iconográficas.

INTERLETRAS, ISSN N 1807-1597. V. 9, Edição número 34. Outubro, 2021/ Março de 2022- p. 


\section{ORGANIZAÇÃO CURRICULAR DO ENSINO PRIMÁRIO: IDEAIS DE CIVISMO, PATRIOTISMO E NACIONALISMO}

A modalidade de escola graduada foi implementada em Porto Velho no ano de $1925 \mathrm{com}$ a criação do Grupo Escolar "Barão do Solimões" por ato do interventor federal do Amazonas, Alfredo Sá, sob a condição de o município oferecer o prédio para instalação da instituição. A inauguração solene realizou-se no dia 19 de agosto, sendo presidida pelo Secretario da Diretoria da Instrução Publica do Estado do Amazonas, Gentil Augusto Bittencourt. A primeira diretora nomeada foi Nathalia de Miranda Queiroz e as aulas iniciaram em setembro do referido ano, com 64 crianças matriculadas, assim distribuídos: Curso Preliminar - Professora Laura Arraes de Lima Brasil; Primeiro ano elementar Professora Leontina Santos; Segundo e Terceiro anos elementares - professora/diretora Nathalia de Miranda Queiroz. (ALTO MADEIRA, 1925).

Essa organização atendia o prescrito no Regulamento Geral da Instrução Pública (AMAZONAS, 1926), Título II que trata do Ensino Primário, dividindo-o em dois ciclos: ciclo fundamental e ciclo complementar (Art. 14). No tocante ao ciclo fundamental assim normatizava: "Art.15 - O cyclo fundamental, nos Grupos Escolares, abrangerá o curso preliminar e o curso elementar; nas escolas singulares das cidades e villas e nas escolas ruraes, será constituído pelo curso elementar." (p. 6, grifos no original). No tocante ao curso preliminar essa legislação determinava ainda que: "Art.17 - O curso preliminar será ministrado nas escolas maternaes (jardins da infancia), mantidas nos Grupos Escolares, ou isoladamente, ao ar livre, em jardins, logradouros públicos ou locaes rigorosamente apropriados." (p.6, grifos no original). Para o curso elementar, o regulamento determinava que fosse: "Art. 18 - O curso elementar, dividido em três anos, será ministrado em todos os Grupos e escolas singulares do Estado, constituindo a matéria de ensino nas escolas ruraes." (p. 6-7, grifos no original).

No findar do ano de 1925 o jornal Alto Madeira noticiava que, no primeiro Grupo Escolar de Porto Velho, estavam matriculados 92 alunos, que prestaram exames perante uma comissão composta pelo inspetor escolar, Dr. Arthur Virgilio do Carmo Ribeiro; pela diretora do Grupo, Nathali Miranda de Queiroz e; pelo presidente da Inspetoria Escolar, Dr. Joaquim Augusto Tanajura. Essa imprensa local, justificava ainda que em virtude do pequeno prazo de funcionamento da instituição, os exames tinham como finalidade: “[...] conhecer o grau de aproveitamento dos alunos, para a sua classificação nos diferentes cursos, na matrícula do ano vindouro.” (ALTO MADEIRA, edição n.874, 1925, p. 2)

De acordo com o Regulamento Geral da Instrução Publica (AMAZONAS, 1926), os programas de ensino para o curso primário deveriam ser "Art. 121 - [...] elaborados anualmente, aplicando os methodos mais recentes e apropriados ao aperfeiçoamento da instucção primaria." Durante esta pesquisa só foi possível localizar os Programas Adotados pelo Conselho Superior de Instrução nos anos de 1930, 1932 (reprodução de 1930) e 1934, cujos documentos possibilitam vislumbrar como estava organizada a educação primária na época. Na introdução do programa de 1930 o legislador apresenta a visão de escola, de didática e o que os docentes encontrariam neste documento: "a orientação didactica de cada disciplina”, mas ressalta: “[...] não está patente a dosagem

INTERLETRAS, ISSN N 1807-1597. V. 9, Edição número 34. Outubro, 2021/ Março de 2022- p. 
de cada lição, tomada á medida do desenvolvimento infantil. Compete insto a inteligência de quem ensina. Daí, a necessidade dos "tests", para a conveniente divisão e subdivisão de uma classe.” (AMAZONAS, Programa..., 1930, p. 4, grifos no original).

No tocante as disciplinas que deveriam ser ministradas no ensino primário o referido Programa apresenta inicialmente, de forma mais ampla, os aspectos metodológicos que deveriam ser adotadas em cada uma, como assuntos, indicação de métodos, cartilhas, livros e os princípios a serem observados. A organização curricular deste programa estava assentada em 13 disciplinas. Dentre estas, selecionamos para este texto: História Pátria, Geografia, Educação Moral e Cívica, Educação Phisica, Educação Hygienica e Canto, por serem representativas da educação idealizada pelos governantes para a infância, cujas finalidades consistiam em cultivar o civismo, o patriotismo e o nacionalismo, influenciando na formação moral e cívica dos alunos das escolas primárias.

Voltada para a formação patriótica e cívica, a disciplina História Pátria era considerada pelo legislador como essencial para despertar "[...] sempre, na criança, a admiração, o culto cívico [...]" aos homens considerados como "notáveis" "heróicos", cujas biografias recomenda que fossem "[...] narradas, em linguagem muito simples adequada ao entendimento infantil." (AMAZONAS, Programas... 1930, p.21). O professor para ministrar esta disciplina deveria observar, entre outros, o seguinte preceito: " $1^{\circ}$ que o professor tenha o coração cheio de patriotismo e bata frequentemente pela verdade, pela justiça e pelo dever" (Idem, p. 22), sendo considerado como um exemplo a ser imitado pelas crianças. E para o ensino das lições recomendava-se a conferência intitulada " $\mathrm{O}$ ensino da História Pátria na Escola Primária”, proferida em 1927, pelo professor Arthur Mendes de Aguiar, da Bahia.

Seguindo na mesma linha de formação, a disciplina de Educação Moral e Cívica reforçava que paralelo as demais de cunho intelectual, deveriam ser ministradas "[...] o ensino moral e cívico, como preparo dos sentimentos na formação do caráter e no amor à Pátria." (AMAZONAS, Programas... 1930, p. 32). Apresentava ainda todos os deveres que o aluno deveria cumprir e a finalidade da educação moral: “[...] extinguir em nós, os instintos da animalidade, tornando-nos brandos, doceis, atenciosos, magnânimos, caritativos, resignados e sinceros." (Idem, p. 33). Novamente no programa desta disciplina era atribuído ao professor o papel de servir de modelo comportamental para a criança e que, nas outras disciplinas como a Geografia e a História do Brasil, encontraria "muitas lições de civismo", recomendando ainda que fosse realizada a leitura em sala de aula do " $[\ldots . .$.$] excelente livro de Affonso Celso, 'Porque me ufano do meu Paiz',$ certamente, encontrarão, nas suas páginas, motivos de nos orgulharmos da terra em que nascemos e da gente que a domina. Cantem-se os nossos hinos patrióticos." (Idem, p. 34). Por fim, para o cultivo dos sentimentos morais e cívicos, o programa dessa disciplina recomendava que fosse organizado nas escolas a criação da "Liga da Bondade", uma associação de crianças destinada a prática da virtude ao culto da Pátria.

Outra disciplina que fazia parte da organização curricular voltada para a formação moral e cívica denominava-se de "Canto". Logo no início do programa, o legislador chama atenção do professor para o ensino nas escolas e a função dos exercícios: "Não

INTERLETRAS, ISSN N 1807-1597. V. 9, Edição número 34. Outubro, 2021/ Março de 2022- p. 
menospreze o professor os exercícios de canto ensinados por audição. Eles educam a voz e tem uma grande influência na formação moral e cívica dos estudantes." (AMAZONAS, Programas..., 1930, p. 46). Quais seriam então as canções idealizadas pelos governantes para que fossem ensinadas às crianças? "Não é qualquer canção que se deve dar a uma criança, para repetir. [...] O verdadeiro canto escolar é brando, cadencioso." (Idem, p. 46).

O legislador recorre aos programas de ensino primário adotado nas escolas do Estado de Minas Gerais em 1925 elencando oito preceitos que poderiam ser adotados pelos mestres amazonenses na referida disciplina. Dentre estes, destaco:

$\left.6^{\circ}\right) \mathrm{O}$ exercício de canto deverá ser diário, não excedendo, porém, de cinco a oito minutos. $7^{\circ}$ ) As músicas adotadas devem ser simples e fáceis. A princípio servirão as próprias cantigas populares, ordinariamente entoadas pelos alunos em seus brinquedos. $8^{\circ}$ ) Só depois que as vozes estiverem mais firmes e claras, iniciará o professor o canto dos hymnos e de outras músicas mais fortes e difíceis, observadas, porém, cuidadosamente, a capacidade das crianças para tal exercício. (AMAZONAS, Programas..., 1930, p. 47).

Por fim, recomendava ao professor:

\begin{abstract}
Particular cuidado deve inspirar ao docente a execução dos nossos hymnos, sobretudo, o Nacional e o da Bandeira, para que eles possam ser interpretados com a significação emotiva e patriótica que eles encerram. É descabível o exagero, grotesco e trágico, com que, gritando mais do que cantando, tentam as vezes, executá-los em nossas escolas. Convém não perder de vista que os nossos hymnos e canções, qualquer que seja sua forma, são pedaços da nossa alma a vibrar pelos impulsos do nosso coração, como pela brasilidade do nosso Povo. (AMAZONAS, Programas..., 1930, p. 47)
\end{abstract}

Apesar da visibilidade dada à música e à Educação Musical durante o período de Era Vargas, os estudos de Vera Jardim (2008) trazem à luz indícios das prescrições e práticas que existiram anteriores a 1930, que se compuseram de um amplo conjunto de dispositivos legais que regulamentaram o ensino musical como disciplina escolar no currículo das escolas públicas de 1889 a 1930, dos métodos e materiais didáticos oficialmente instituídos e das prescrições para o seu ensino nas escolas públicas. De acordo com Jardim (2008), ao analisar os álbuns de música, concluiu que, inicialmente, foi incorporada nos processos escolares por seu valor educativo e, no projeto republicano, assumiu a função de propagar a cultura cívica, transmitindo mensagens de orgulho, coragem e patriotismo, como também, da música culta, predominantemente europeia, para a experiência das crianças.

Para além da formação moral, cívica e patriótica idealizada pelos governantes, consta também no Programa de ensino primário a disciplina "Educação Phisica" voltada para a "educação dos corpos infantis" (SÁ, 2018), almejando obter no futuro "[...] homens regularmente desenvolvidos, sadios, enérgicos e predispostos para a ação." (AMAZONAS, Programas..., 1930, p. 35). Competia então, ao professor primário, “[...] consciente do seu papel e da responsabilidade que assume ao commandar seus discípulos, deve ser um estudioso dos princípios, em que se fundamenta esse 
desenvolvimento, applicáveis como gymnastica escolar.” (Idem, p. 36, grifos no original). O legislador recomendava então, como os exercícios deveriam ser feitos:

\begin{abstract}
Os exercícios gymnasticos devem ser executados de preferência, no pateo da escola, ao ar livre, para que as crianças possam respirar bem o ar oxigenado, abrigadas dos raios solares. Devem ser diários, uma ou duas vezes, nos intervalos das aulas, após as lições que obrigaram, por algum tempo, à immobilidade. As marchas rytmadas, acompanhadas de cânticos, são agradáveis aos estudantes. (AMAZONAS, Programas..., 1930, p. 36).
\end{abstract}

O programa desta disciplina afirmava ainda que: “[...] a gymnastica, tão indispensável do berço ao túmulo, o melhor preventivo contra a inercia ou contra a vida sedentária, é, ao lado da prophylaxia e da hygiene, o factor mais poderoso da eugenia, do apuramento da nossa raça." (AMAZONAS, Programas..., 1930, p. 37). No tocante a "gymnastica escolar", o programa trazia como orientação didática que fosse observado o plano de autoria do professor Augusto Ribeiro de Campos, Inspector de Exercícios Physicos de São Paulo, no qual recomendava: "As lições devem ser completas. [...] Os característicos da lição completa são os seguintes: - a lição deve ser continua, alternada, gradual, attrahente e disciplinada." (Idem, p. 37, grifos no original).

A preocupação com o corpo e com a higiene das crianças estava presente também na organização curricular do ensino primário por meio da disciplina "Educação Hygienica", com a defesa de que:

A saúde, sendo condição indispensável para o trabalho e para a felicidade humana, exige uma defesa que ninguém deve desconhecer. Nela, reside toda a alegria de viver. Sem ela, o progresso deixaria de existir, visto com o indivíduo enfermo é unidade morta, desvalorizada, na marcha da civilização." (AMAZONAS, Programas..., 1930, p. 43).

Como a escola poderia garantir a saúde às crianças? Essa questão também foi idealizada pelo legislador no Programa de Ensino Primário, para que nas escolas fossem concretizadas tais ações ao defender:

Pode-se garantir a saúde, mediante preceitos de prophylaxia e hygiene. São esses que a escola, a título de conselhos, em palestras oportunas, dará à criança, chamando-lhe a atenção para os hábitos de asseio e os meios de evitar contaminação. O professor exigirá dos seus alunos que andem sempre limpos, mãos bem lavadas, unhas aparadas. Não é mal que se institua a revista de asseio, como revivescência das nossas velhas escolas de outrora. (AMAZONAS, Programas..., 1930, p. 43, grifos no original).

Neste quesito, há uma defesa no Programa de que o ensino referente aos cuidados sanitários e de profilaxia individual nas escolas poderiam ser praticados pelas crianças fora das instituições, nas suas casas, na rua e em outros espaços, inculcando assim hábitos que pudessem influenciar na saúde infantil, uma vez que: “[...] O que hoje foi um acto, amanhã poderá ser um hábito, se não for evitada a repetição. Assim, a má posição de sentar-se, escrever, gesticular, andar, alimentar-se, beber, respirar, etc, quando feitos anormalmente, trarão consequências danosas à saúde." (Idem, p. 43, grifos no original). 
Na década inicial do século $\mathrm{XX}$, as crianças que viviam na região do Guaporé eram "poucas" ou "inexistentes" e as poucas que se viam pela cidade tinham uma vida curta, pois eram ceifadas pelas moléstias, como relatado por Oswaldo Cruz em 1910. Este cenário era possível se ser encontrado em muitas outras regiões do Brasil, pois várias pesquisas apontam o elevado índice de mortes de crianças que tiveram suas vidas ceifadas na tenra infância. Neste sentido, houve um investimento na instrução e na educação com medidas voltadas para se buscar manter os indivíduos saudáveis para trabalharem pela construção do progresso da nação. (SOUZA, R., 2002). Essa prática ganhou notoriedade na Era Vargas, período em que nos discursos se disseminava os ideais de higienismo, de raça, de homogeneização, de nacionalização e de crescimento da nação.

Neste sentido, a disciplina "Educação Hygienica" que compunha o currículo do ensino primário recomendava as leituras: "Hygiene Escolar", de Leo Burgesrtein, trad. hespanhola do Dr. Eugenio Jaumandreu y Luiz Sanchez Sarto, de 1929 e; "Codigo de Saude, Preceitos de Hygiene", do Dr. R. Chapot-Prevost, de 1924 pontuando ainda que:

\footnotetext{
As crianças também não devem prescindir de conselhos, quanto à prophylaxia de moléstias contagiosas e de outras, apenas de caráter endêmico, sobretudo no interior do Estado. Diga-lhes como evitar a morphea, a tuberculose, o impaludismo, a verminose e algumas outras formas clínicas, que afligem muitos de nossos compatrícios.

$\mathrm{Na}$ integridade da saúde dos nossos escolares está, em grande parte, o futuro do Brasil... (AMAZONAS, Programas..., 1930, p. 43-44).
}

No ano de 1932, os Programas do Ensino Primário adotados pelo Conselho Superior de Instrução Pública no Estado do Amazonas, sofreu algumas alterações. A introdução tem o mesmo teor do ano anterior e com as mesmas disciplinas. A diferença consiste na retirada do Programa para o Jardim da Infância, na substituição dos Programas para o Curso Médio pelos Programas e indicações para o Curso Definitivo $\left(1^{\circ}\right.$ e $2^{\circ}$ ano). Mas as disciplinas tratadas neste artigo permaneceram com os mesmos ideais. E, no Programa adotado em 1934, houve a inclusão do termo "Pré-primário", e, foi dividido nas seguintes partes: $1^{\mathrm{a}}$ ) Escola primária elementar - noções de metodologia do ensino; $2^{\mathrm{a}}$ ) PlanosProgramas de Educação Pré-primária (Jardins da Infância); $3^{\text {a }}$ ) Planos-Programas de Ensino Primário, subdivido em Curso Elementar ( $1^{\circ}$ e $2^{\circ}$ ano), Curso Definitivo $\left(1^{\circ}\right.$ e $2^{\circ}$ ano).

\section{PRÁTICAS DE MILITARIZAÇÃO DA INFÂNCIA NO COTIDIANO ESCOLAR DAS ESCOLAS PRIMÁRIAS DE PORTO VELHO-RONDÔNIA}

Durante o período investigado observa-se que a imprensa exerceu um papel relevante na divulgação das práticas realizadas pelas escolas primárias. Com base no Programa das disciplinas acima, podemos inferir que as práticas de militarização eram instituídas nas sessões cívicas referentes a todos os feriados nacionais e estaduais, com o objetivo de preparar os alunos para a participação nas festas cívicas. Os escolares participavam de todos os momentos festivos em comemoração as datas cívicas (Semana da Pátria, Dia do Soldado, 7 de Setembro, Dia da Bandeira, aniverssários de autoridades), com desfiles de 
batalhões em marcha, bandeiras e com vasto programa festivo que eram disseminados na imprensa periódica local:

\begin{abstract}
A Semana da Pátria em Porto Velho
Ao romper da aurora de 7 de setembro, dia maior da nossa Pátria, a banda de clarins da $3^{\text {a }}$ Companhia do $2^{\circ}$ Batalhão de Fronteiras, ao pé do Monumento da Independência, à praça Major Guapindaia, soltou as vibrantes notas do toque de alvorada, seguidas do rufar marcial dos tambores. Era a primeira saudação erguida ao Brasil, na data em que ele celebra a sua emancipação política, registrada nos anais da História há anos passados. [...]

Às sete e meia horas, ao pé do Monumento, o Reverendo Padre Angelo Cerri, vigario da paróquia celebrou missa. Ali formaram os Colégios D. Bosco e Maria Auxiliadora, o Grupo Escolar Barão do solimões, a Escola Madeira Mamoré [...] precedidos da banda de clarins e tambores. [...]

Terminada essa cerimônia, seguiu-se o desfile da tropa, colégios, [...] O sr. Capitão Aluizio Ferreira, Inspetor da Companhia de Fronteiras e Diretor da E.F, Madeira Mamoré, [...] passou revista á força federal e demais agremiações [...] Iniciada a marcha, percorreu o prestito a avenida sete de setembro - onde estava levantado o coreto para as autoridades. (ALTO MADEIRA, edição n. 2223,1938 , p. 1).
\end{abstract}

Práticas semelhantes se repetiam como podemos visualizar nas imagens abaixo, representa um desfile cívico com a presença de alunos de todas as escolas da cidade de Porto Velho, uniformizados, com bandeiras em punho, enfileirados recepcionando o presidente Getúlio Vargas em outubro de 1940:

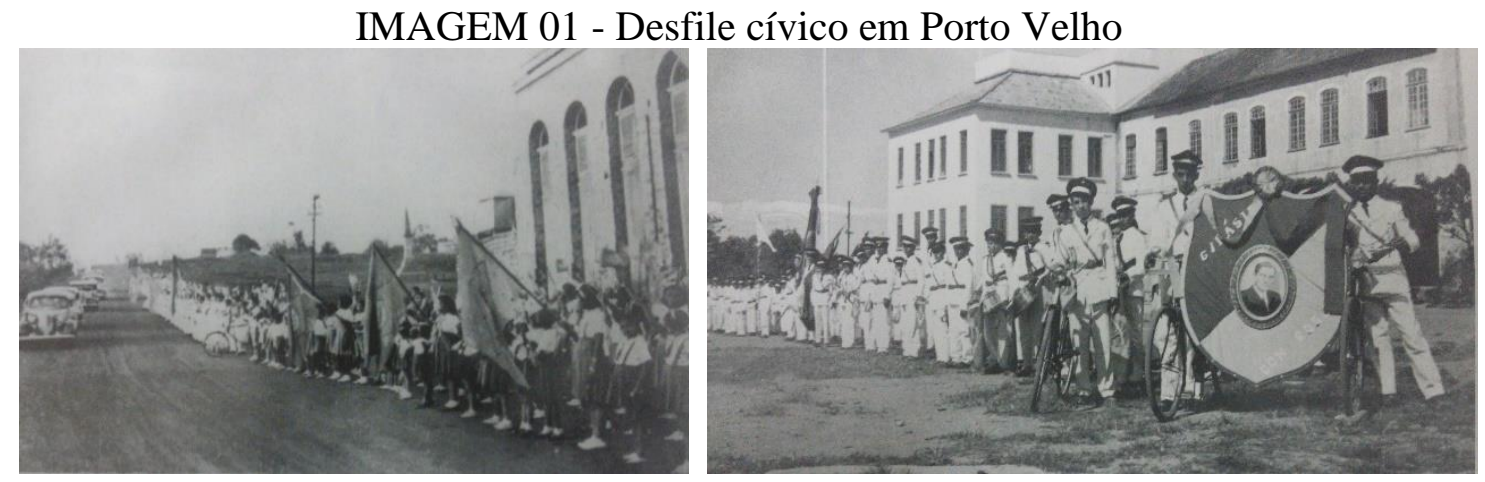

FONTE: Brito, Luiz. Revelando Porto Velho, 2004

Os desfiles cívicos são recorrentemente anunciados na impresa, com a presença de todas as instituições escolares da cidade, alunos e professores. Nos programas dos festejos, a relação das atividades eram várias, indo desde os desfiles militares e escolares, hasteamento da bandeira, canto dos hinos (Nacional, da Bandeira), banda de música, tambores e corneteiros, salva de 21 tiros, cabo de guerra, torneios militares e esportivos e bailes, cujo convites se estendiam para as atuoridades civis, militares, consulares e todo o povo. Nos programas foi possível localizar também, que fazia parte da programação a "demonstração de educação física pelos Colégios da Prelazia" (ALTO MADEIRA, edição 2427, 1940, p. 3). 
Quanto ao escotismo, no Amazonas, a exemplo do ocorreu em São Paulo (SOUZA, R., 2002), Minas Gerais, Espirito Santo, houve a criação de uma Liga Amazonense de Escoteiros em 1915. Mas no deccorer desta pesquisa, não foi possível localizar práticas, nem a introdução oficial de associações escoteiros nas escolas primárias de Porto Velho, somente alguns indicícios de uma Associação Guaporense de Escoteiros em 1946 (ALTO MADEIRA, edição 2991, 1946). Mas seguindo as instruções dos Programas do Ensino Primário (AMAZONAS, 1930), foi criada pelos escolares de Porto Velho, no ano de 1926 a "Liga da Bondade Barão do Solimões", sob a orientação da diretora Ambrosina Cantanhede. A associação foi composta por alunos do Grupo Escolar do mesmo nome, mas "[...] permitia a inscrição de sócios contribuintes de outros Grupos e escolas isoladas e a inscrição de estranhos como sócios protetores ou beneméritos." (ALTO MADEIRA, edição 962, 1926, p. 2). Sob a assistência e orientação da diretora do Grupo e de suas auxiliares foi realizado a eleição da diretoria desta Liga pelos seguintes alunos: Simpliciano Silva, Presidente; Nevelina Moncho, Vice-presidente; Edmundo Pas e Jofre Tháles, $1^{\circ}$ e $2^{\circ}$ secretários; Flávio Milne Jones, tesoureiro; Osvaldo Santos e Francisco Aguiar, vogais. A posse ocorreu em 12 de setembro de 1926, em sessão solene na sede do Grupo Escolar, sendo convidados as autoridades, os cônsules, a imprensa, os chefes de repartição, inspetores escolares e as famílias dos alunos e mais pessoas gradas do meio social. (Idem).

\section{CONSIDERAÇÕES FINAIS}

Ao analisar a organização curricular das disciplinas elencadas acima é possível inferir que: "o modo pelo qual se acham organizados, delimitados, classificados, separados, os saberes veiculados na escola influencia, com efeito, a construção da identidade entre os alunos." (FORQUIN, 1993, p. 90).

No contexto deste artigo foi possível perceber que a constituição dos saberes escolares selecionados para compor o programa curricular das escolas primárias de Porto Velho, no período em que estava sob a jurisprudência do Estado do Amazonas, demonstra a materialização da representação de educação da infância dos governantes e dos intelectuais da região amazônica, por meio dos documentos oficiais e dos jornais da época buscaram inculcar práticas que consideravam como ideais para a formação das crianças.

As prescrições nos regulamentos demonstram que desde a primeira República buscavase moldar as crianças (em todos os aspetos, no falar, no sentar-se, no andar, ao cantar), com disciplina e ordenamento, projetando nelas o cidadão patriótico que contribuiria para o progresso da nação. Essas práticas foram reforçadas na Era Vargas, que para engrandecer seus feitos, investiu nas propagandas e na normatização de dispositivos que pudessem fortalecer seus ideais de nacionalismo, civismo, patriotismo, higienismo.

\section{REFERÊNCIAS}


ALTO MADEIRA. Jornal Independente. Porto Velho: Alto Madeira, 1917-1930. Edições consultadas no Acervo físico do Museu da Memória de Rondônia e da Biblioteca Nacional Digital.

Disponível em: http://memoria.bn.br/DocReader/DocReader.aspx $? \mathrm{bib}=060160 \&$ Pasta $=\& P e s q=a l t o \% 20$ madeira. Acesso em: 18 abr. 2020.

AMAZONAS. Regulamento Geral da Instrucção Publica. Lei n.984, de 14/10/1918, alterada pelos Decretos n.105, de 19/11/1925, n.3 de 18/01/1926 e Lei n. 1.299, de 18/10/1926. Manaus: Typographia dos Armazens Palacio Real, 1926. 1930. Disponível em:

https://www.fcc.org.br/pesquisa/educacaoInfancia/EducacaoInfancia.downloadArtigo.m tw?id=1210. Acesso em: 22 abr. 2020.

Programas do Ensino Primário. Adotados pelo Conselho Superior de Instrução Pública em 7 de fevereiro de 1930. Manaus: Imprensa Publica, 1930. Disponível em: https://www.fcc.org.br/pesquisa/educacaoInfancia/EducacaoInfancia.downloadArtigo.m tw?id=1210. Acesso em: 22 abr. 2020.

Programas do Ensino Primário. Adotados pelo Conselho Superior de Instrução Pública em 28 de janeiro de 1932. Manaus: Imprensa Publica, 1932. Disponível em: https://www.fcc.org.br/pesquisa/educacaoInfancia/EducacaoInfancia.downloadArtigo.m tw?id=1210. Acesso em: 22 abr. 2020.

Planos-Programas e Indicações do Ensino Pré-Primário e Primário. Aprovados pelo Conselho Superior de Instrução. Manaus: Imprensa Publica, 1934. Disponível

em: https://www.fcc.org.br/pesquisa/educacaoInfancia/EducacaoInfancia.downloadArtigo.m tw?id=1210. Acesso em: 22 abr. 2020.

BRASIL. Decreto-lei $\mathbf{n}^{\mathbf{0}} \mathbf{7 . 7 7 2}$, de 23 de julho de 1945. Dispõe sobre a organização administrativa do Território Federal do Guaporé e dá outras providências. Disponível em: https://www2.camara.leg.br/legin/fed/declei/1940-1949/decreto-lei-7772-23-julho1945-457557-publicacaooriginal-1-pe.html. Acesso em: 22 abr. 2020.

BRITO, Luiz. Revelando Porto Velho. Porto Velho: Brasil Telecom, 2004.

CERTEAU, Michel de. A escrita da história. Rio de Janeiro: Forense Universitária, 1982.

CHARTIER, Roger. A história cultural: Entre práticas e representações. Lisboa: Difel, 1990.

O mundo como representação. Estudos Avançados, 5 (11), p. 173-191, 1991. Recuperado de https://www.revistas.usp.br/eav/article/view/8601. Acesso em: 22 abr. 2020. 
CHERVEL, A. História das disciplinas escolares: reflexões sobre um campo de pesquisa. Teoria \& Educação, 2, 177-229, 1990.

CRUZ, Oswaldo Gonçalves. Considerações geraes sobre as condições sanitarias do Rio Madeira. Rio de Janeiro: Papelaria Americana, 1910. Acervo Casa de Oswaldo Cruz: obras raras.

FORQUIN, Jean-Claude. Escola e Cultura: as bases sociais e epistemológicas do conhecimento escolar. Porto Alegre: Artes Médicas, 1993.

GOODSON, I. A construção social do currículo. Lisboa: Educa, 1997.

Currículo: Teoria e história. Petrópolis: Vozes, 1995.

JARDIM, Vera Lucia Gomes. Da arte à educação: a música nas escolas públicas - 18381971. 2008. 322 f. Tese (Doutorado em Educação) - Pontifícia Universidade Católica de São Paulo, São Paulo, 2008.

SOUZA, Rosa Fátima de. A militarização da infância: Expressões do nacionalismo na cultura brasileira. Cadernos Cedes, online, v. 20, n. 52, p. 104-121, nov./2000. Disponível em: https://www.scielo.br/pdf/ccedes/v20n52/a08v2052.pdf. Acesso em: 22 abr. 2020.

SOUZA, Valdir Aparecido de. (Des) ordem na fronteira: ocupação militar e conflitos sociais na bacia do Madeira-Guaporé (30/40). 2002. 175 f. Dissertação (Mestrado em História e Sociedade) - Universidade Estadual Paulista "Júlio de Mesquita Filho", São Paulo, 2002.

SÁ, Elizabeth Figueiredo. A educação dos corpos infantis no projeto Mato-grossense de formação do cidadão Republicano (1910-1930). Cad. Cedes, Campinas, v. 38, n. 104, p. 75-88, jan.-abr., 2018.

* Professora Adjunta efetiva, lotada na Universidade Federal de Rondônia (UNIR), coordenadora do Grupo de Estudos e Pesquisa em História da Educação de Rondônia (GEPHERO) e Pesquisadora do Grupo de Pesquisa História da Educação e Memória (GEM). Doutora em Educação pela Universidade Federal de Mato Grosso (2015). Orcid Id: https://orcid.org/0000-0002-6031-4314. 